\title{
Heterotrophy and Nitrogen Fixation in Chlorogloea fritschii
}

\author{
By P. FAY \\ Department of Botany, Westfield College, University of London
}

(Received 30 September 1964)

\begin{abstract}
SUMMARY
The blue-green alga Chlorogloea fritschii fixed elementary nitrogen to a limited extent in the dark in a strictly inorganic medium. Growth and nitrogen fixation continued in the dark when a suitable organic substrate was present in the medium. Among the organic substrates tested, sucrose $(0.01 \mathrm{M})$ was the most readily utilized and was outstanding in supporting nitrogen fixation in the dark. The alga was adapted to heterotrophic conditions after continuous incubation and repeated subcultivation in the dark. Inter-relations between carbon assimilation and nitrogen fixation under heterotrophic conditions were observed. Sucrose assimilation proceeded more vigorously in the light and resulted in a fourfold increase in the rate of growth and nitrogen fixation. Sucrose assimilation was increased in the light in the absence of carbon dioxide from the gas phase, but nitrogen fixation was greatest when the alga was supplied with sucrose and carbon dioxide. Carbon dioxide was inhibitory to sucrose assimilation and slightly to nitrogen fixation in the dark.
\end{abstract}

\section{INTRODUCTION}

The frequent occurrence of blue-green algae in soils and in habitats rich in organic matter has for long suggested that they might grow in the dark at the expense of organic nutrients (see Fogg, 1956). Although Allison, Hoover \& Morris (1937) reported a strain of Nostoc muscorum able to grow and fix nitrogen on glucose in the dark, no detailed studies were given. Investigations of the heterotrophic growth of Tolypothrix tenuis by Kiyohara, Fujita, Hattori \& Watanabe $(1960,1962)$, another blue-green alga known for its ability to fix molecular nitrogen, were made in the presence of combined nitrogen but no account was given about attempts to grow the alga in nitrogen-free medium in the dark.

When Fay \& Fogg (1962) found that the blue-green alga known as Chlorogloea fritschii (but see Fay, Kumar \& Fogg, 1964) was able to fix nitrogen not only in the light but also in the dark, it was thought desirable to examine the conditions of heterotrophic growth and nitrogen fixation by this alga.

\section{METHODS}

Organism, culture and general analytical methods. The strain of alga, culture methods, growth conditions and general methods for the estimation of growth and nitrogen fixation used were as described previously (Fay \& Fogg, 1962; Fay et al. 1964).

Media containing organic substrates were autoclaved at $115^{\circ}$ for $15 \mathrm{~min}$. Bacteriological filters or exposure to ultraviolet radiation were used to sterilize volatile or 
thermolabile compounds. The concentration of reducing sugar in autoclaved medium containing sucrose was below $1 \%$ of the total sugar content of the medium. Phosphate solutions were sterilized separately and added after cooling to the sterile medium.

Sugar determinations were carried out according to the Hagedorn-Jensen method as modified by Hulme \& Narain (1931).

Nitrogen starvation. For certain experiments nitrogen-starved organisms, which showed an increased response when exposed to elementary nitrogen, were used. Organisms from exponentially growing cultures were separated by centrifugation, washed with distilled water, centrifuged down again, and resuspended in fresh standard medium. The suspension was then flushed with argon containing about $2 \%(\mathrm{v} / \mathrm{v}) \mathrm{CO}_{2}$ for $1 \mathrm{hr}$ and incubated overnight under the same gas phase at $30^{\circ}$ and illuminated with about 500 foot-candles light intensity.

${ }^{15} \mathrm{~N}$ technique for the determination of nitrogen fixation. This was as described by Burris \& Wilson (1957). The algal suspensions were placed in reaction flasks and attached to a closed culture apparatus which was provided with magnetic stirring or shaking mechanism and held under controlled conditions of temperature. Then the vessels were evacuated and filled to atmospheric pressure with a gas mixture containing ${ }^{15} \mathrm{~N}_{2}$-enriched nitrogen gas. When a constant $0.2 \%(\mathrm{v} / \mathrm{v}) \mathrm{CO}_{2}$ concentration in the gas phase was required a ' $\mathrm{CO}_{2}$ buffer' (Pardee, 1949) was added to the side arm of the reaction flask. After exposure to ${ }^{15} \mathrm{~N}_{2}$ the samples were digested by the Kjeldahl method, the ammonia distilled into standard acid and the ammonium-nitrogen converted to elementary nitrogen with alkaline hypobromite. The ${ }^{14} \mathrm{~N}:{ }^{15} \mathrm{~N}$ ratio was determined with a MS 3 type (Associated Electrical Industries Ltd., Manchester) mass-spectrometer.

Radioactivity assays. To follow sucrose assimilation, $(\mathrm{U})^{14} \mathrm{C}$-sucrose (supplied by the Radiochemical Centre, Amersham, Buckinghamshire) was added to the algal suspension and the incorporation of ${ }^{14} \mathrm{C}$ into cell material and the radioactivity of the respiratory $\mathrm{CO}_{2}$ was measured after incubation. To measure incorporation of ${ }^{14} \mathrm{C}$-sucrose, samples of the algal suspension were filtered through membrane filters $(0.5-1 \cdot 0 \mu$ pore size) which were then washed with distilled water and dried over silica gel and soda lime in a desiccator. Radioactivity was measured with a Tracerlab SC-50 B (Tracerlab Inc., Massachussets) automatic gas-flow proportional counter. The concentration of algal samples taken was chosen so that a thin uniform deposit of the particulate matter was obtained, in a range in which self absorption was found insignificant and thus corrections for self absorption could be omitted.

Respiratory $\mathrm{CO}_{2}$ was trapped in alkali $(10 \% \mathrm{NaOH}$ or $12 \% \mathrm{KOH})$ placed in the side arm of the reaction flasks and converted to barium carbonate. The barium carbonate precipitate was collected on a membrane filter, rinsed with hot distilled water and fixed with a dilute glue solution. The samples were then dried and the radioactivity measured. The dried barium carbonate precipitate was weighed and corrections were applied for self absorption by using a self-absorption curve. 


\section{RESULTS}

Search for organic substrates supporting growth and nitrogen fixation in the dark

Various compounds were tested for their ability to support growth of the alga in the dark, in the presence and in the absence of combined nitrogen (Table 1). On first transfer from the light, growth in the dark was in general very slow. No significant changes were observed during the first 4 weeks. However, growth proceeded slowly on some of the substrates during the second and third month in the dark. Slight growth occurred on mannitol + nitrate, on glucose + nitrate, on glycine + and - nitrate, and on glutamine + and - nitrate. There was appreciable growth on maltose with nitrate but not without. Best growth was on sucrose in the presence and in absence of combined nitrogen. Sucrose was outstanding among the substrates tested in allowing a substantial fixation of elementary nitrogen in the dark.

Table 1. Utilization of organic substrates by Chlorogloea fritschii incubated at $30^{\circ}$ in the dark for 3 months in the presence and absence of combined nitrogen in the basic medium

Substrate concentration: $0.01 \mathrm{~m} ;+,++,+++=$ growth; $0=$ no growth.

\begin{tabular}{lcc} 
& \multicolumn{2}{c}{ Medium } \\
\cline { 2 - 3 } Substrate & $+\mathrm{NO}_{3}$ & $\mathrm{~N}$-free \\
Mannitol & + & $\mathbf{0}$ \\
Glucose & + & $\mathbf{0}$ \\
Sucrose & +++ & ++ \\
Maltose & ++ & + \\
Glycine & + & + \\
Glutamine & + & +
\end{tabular}

Growth with acetate, pyruvate, citrate, $\alpha$-ketoglutarate, succinate, fumarate, malate, glycollate, arabinose, fructose, glutamate and aspartate was nil.

The effect of substrate concentration upon growth and nitrogen fixation in the dark

The effect of sucrose on growth after 10 weeks incubation at $35^{\circ}$ in the dark paralleled its effect on nitrogen fixation (Fig. 1); 0.01 M-sucrose was best for both. Attempts to grow the alga with an identical molar range of glucose, fructose, glucose + fructose in equimolar mixture or of fructose-1,6-diphosphate in the dark had little or no success. Only glucose $(0 \cdot 1 \mathrm{~m})$ supported appreciable growth and nitrogen fixation in the dark.

\section{Assimilation of ammonium-nitrogen, nitrate-nitrogen and elementary nitrogen} during growth on glucose and on sucrose in the dark

Considerable differences occurred in growth and nitrogen assimilation of the alga in the dark, according to the organic substrate and the source of nitrogen supplied (Table 2). Growth and nitrogen assimilation were best with sucrose (0.01 M)+ nitrate, being 4 to 5 times the values obtained with ammonium or elementary 
nitrogen; \% cell-N, however, was highest with ammonium and lowest in nitrogenfree medium. Glucose $(0.1 \mathrm{M})$ supported an approximately equal growth with all three sources of nitrogen but appreciable nitrogen assimilation occurred only in the presence of ammonium-nitrogen. Ammonium-nitrogen was assimilated by the alga to a similar extent with sucrose or glucose. Nitrate reduction and nitrogen fixation, however, were active in the presence of sucrose but hardly at all with glucose.

Table 2. Growth and nitrogen assimilation of Chlorogloea fritschii after 6 reeks at $30^{\circ}$ in the dark on sucrose and on glucose with various sources of inorganic nitrogen

\begin{tabular}{|c|c|c|c|c|}
\hline \multirow[b]{2}{*}{$\begin{array}{c}\text { Organic } \\
\text { substrate }\end{array}$} & \multirow[b]{2}{*}{$\begin{array}{c}\text { Source } \\
\text { of } \mathbf{N}\end{array}$} & \multirow[b]{2}{*}{$\begin{array}{l}\text { Dry wt. of } \\
\text { alga (mg.) }\end{array}$} & \multicolumn{2}{|c|}{ Nitrogen content of alga } \\
\hline & & & mg. & $\begin{array}{l}\% \text { of } \\
\text { dry wt. }\end{array}$ \\
\hline \multirow[t]{3}{*}{$0.01 \mathrm{~m}$-Sucrose } & $\mathbf{N H}_{4}^{+}$ & $\left.\begin{array}{l}6 \cdot 6 \\
7 \cdot 3\end{array}\right\}(7 \cdot 0)$ & $\left.\begin{array}{l}0 \cdot 412 \\
0.438\end{array}\right\}(0.425)$ & $6 \cdot 1$ \\
\hline & $\mathrm{NO}_{3}^{-}$ & $\left.\begin{array}{l}56 \cdot 2 \\
53 \cdot 8\end{array}\right\}(55 \cdot 0)$ & $\left.\begin{array}{l}2 \cdot 975 \\
2 \cdot 175\end{array}\right\}(2 \cdot 575)$ & 4.7 \\
\hline & $\mathbf{N}_{2}$ & $\left.\begin{array}{l}13 \cdot 3 \\
13 \cdot 5\end{array}\right\}(13 \cdot 4)$ & $\left.\begin{array}{l}0 \cdot 355 \\
0 \cdot 414\end{array}\right\}(0 \cdot 385)$ & $2 \cdot 9$ \\
\hline \multirow[t]{3}{*}{ 0.1 M-Glucose } & $\mathbf{N H}_{4}+$ & $\left.\begin{array}{l}6 \cdot 0 \\
5 \cdot 9\end{array}\right\}(6 \cdot 0)$ & $\left.\begin{array}{l}0.327 \\
0.305\end{array}\right\}(0 \cdot 316)$ & $5 \cdot 3$ \\
\hline & $\mathrm{NO}_{3}^{-}$ & $\left.\begin{array}{l}6 \cdot 8 \\
6 \cdot 2\end{array}\right\}(6 \cdot 5)$ & $\left.\begin{array}{l}0.049 \\
0.039\end{array}\right\}(0.044)$ & $0 \cdot 7$ \\
\hline & $\mathbf{N}_{2}$ & $\left.\begin{array}{l}3 \cdot 7 \\
5 \cdot 2\end{array}\right\}(4 \cdot 5)$ & $\left.\begin{array}{l}0 \cdot 054 \\
0.068\end{array}\right\}(0.061)$ & $1 \cdot 3$ \\
\hline
\end{tabular}

Physiological adaptation to heterotrophic conditions

It seemed that by continuous incubation and repeated subculture in the dark in the presence of $0.01 \mathrm{M}$-sucrose, the alga gradually adapted to heterotrophic conditions; this was perceptible by the significant decrease of the duration of lag phase and by the better growth of the alga. After subcultivation for one year (six subcultures) in the dark, the lag was about 1 week (Fig. 2). The yield of organism (110 mg. algal dry weight $/ 100 \mathrm{ml}$. medium) after 8 weeks was $50 \%$ greater than that obtained with the non-adapted strain $(76 \mathrm{mg} . / 100 \mathrm{ml}$.) after 10 weeks in the dark.

There seemed to be no lag in nitrogen fixation. The amount of nitrogen fixed ( $6 \mathrm{mg}$. $/ 100 \mathrm{ml}$.) was 3 times that of the non-adapted strain. The greater nitrogenfixing capacity of the alga which followed adaptation to heterotrophic conditions was also apparent from the higher (5-8\%) nitrogen content of the organism, in contrast to the $2-3 \%$ nitrogen content of the non-adapted strain grown in the dark. Extracellular nitrogen was high ( $35 \%$ total-N), as usual, after inoculation but decreased rapidly to $4 \%$ and remained at this value. This was in contrast to the $12-15 \%$ extracellular nitrogen found in light-grown cultures.

\section{Effect of light upon sucrose utilization}

The utilization of sucrose in light by the alga resulted in an increase of the growth rate and a prolongation of the period of exponential growth (Fig. 3). After 5 weeks 


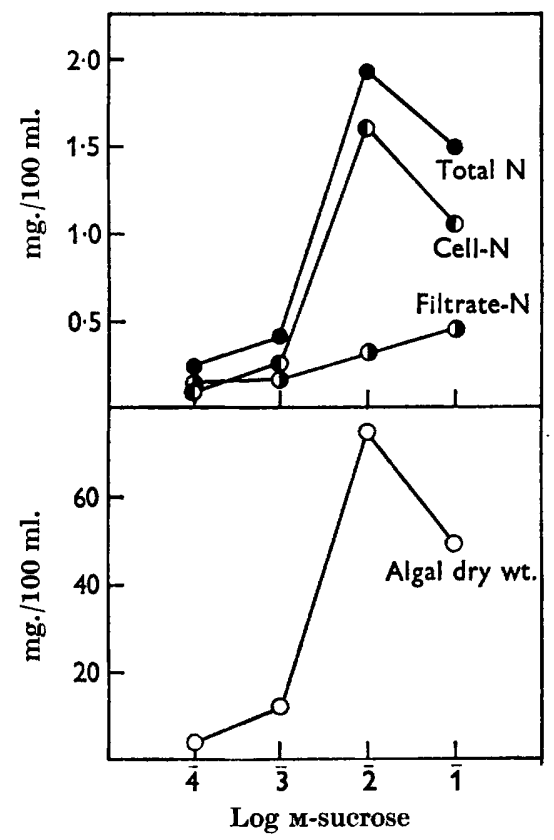

Fig. 1

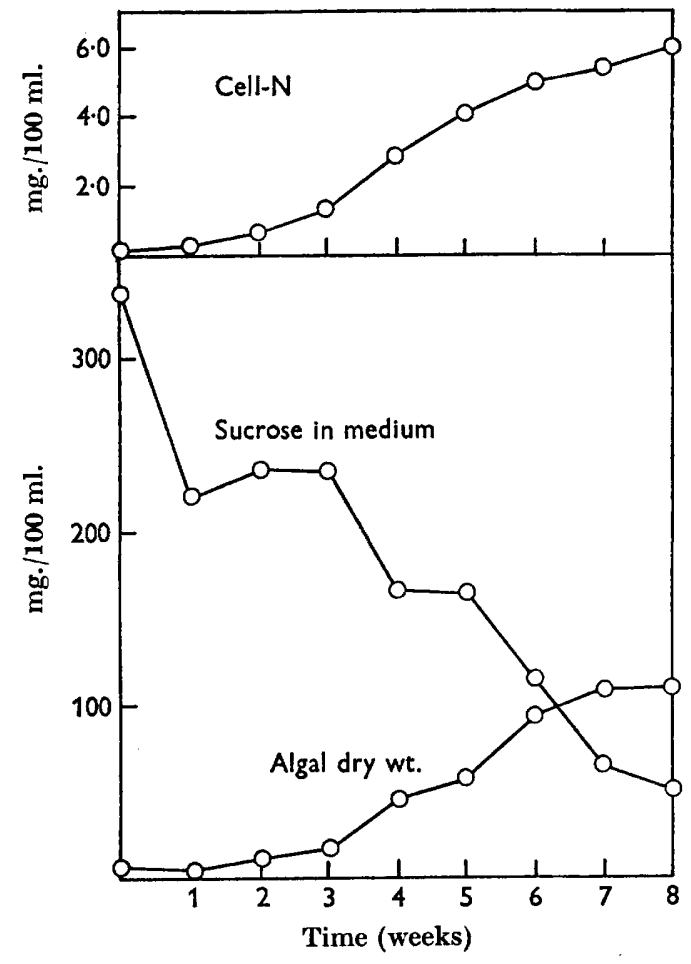

Fig. 2

Fig. 1. Effect of sucrose concentration of the medium on growth (algal dry wt.) and nitrogen fixation (total-N) of Chlorogloea fritschii incubated at $35^{\circ}$ in the dark for 10 weeks.

Fig. 2. Time course of sucrose uptake, growth (algal dry wt.) and nitrogen fixation (cell-N) by a dark-adapted strain of Chlorogloea fritschii incubated in the dark at $30^{\circ}$.

\section{Table 3. Effect of sucrose on ${ }^{15} \mathbf{N}_{2}$ uptake by the light-grown and} dark-adapted strains of Chlorogloea fritschii

$\mathrm{N}$-starved cells were exposed to $\mathrm{N}_{2}$ enriched with $8 \%{ }^{15} \mathrm{~N}_{2}$ at $30^{\circ}$ in the light (200 footcandles) and in the dark, under aerobic and anaerobic conditions, for 3 days. Means in parentheses.

\begin{tabular}{|c|c|c|c|c|}
\hline \multirow[b]{2}{*}{ Strain of alga } & \multirow[b]{2}{*}{ Carbon source } & \multirow[b]{2}{*}{$\mathrm{O}_{2}$} & \multicolumn{2}{|c|}{ Atom $\%{ }^{15} \mathbf{N}_{2}$ excess } \\
\hline & & & In the light & In the dark \\
\hline $\begin{array}{l}\text { Light-grown } \\
\text { Dark-adapted }\end{array}$ & $6 \times 10^{-4} \mathrm{M}-\mathrm{NaHCO}_{3}$ & + & $\left.\begin{array}{l}\left.\begin{array}{l}0 \cdot 498 \\
0 \cdot 462\end{array}\right\}(0 \cdot 480) \\
0 \cdot 306 \\
0 \cdot 336\end{array}\right\}(0 \cdot 324)$ & $\left.\begin{array}{l}0 \cdot 154 \\
0 \cdot 142 \\
0.052 \\
0.063\end{array}\right\}(0 \cdot 148)$ \\
\hline $\begin{array}{l}\text { Light-grown } \\
\text { Dark-adapted }\end{array}$ & $10^{-2} \mathrm{M}$-sucrose & $\begin{array}{l}+ \\
+\end{array}$ & $\left.\begin{array}{l}2 \cdot 394 \\
2 \cdot 364 \\
2 \cdot 280 \\
2 \cdot 340\end{array}\right\}(2 \cdot 379)$ & 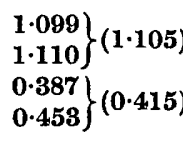 \\
\hline $\begin{array}{l}\text { Light-grown } \\
\text { Dark-adapted }\end{array}$ & $10^{-2} \mathrm{M}$-sucrose & \}$_{-}^{-}$ & $\left.\begin{array}{l}\left.\begin{array}{l}2 \cdot 274 \\
2 \cdot 212\end{array}\right\}(2 \cdot 243) \\
2 \cdot 584 \\
2 \cdot 653\end{array}\right\}(2 \cdot 618)$ & 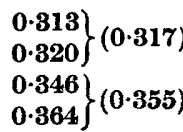 \\
\hline
\end{tabular}


the yield of organism in cultures grown on sucrose was about 4 times that of control cultures; the sucrose concentration decreased by about $90 \%$. The percentage cell-N was not appreciably different in the two culture series.

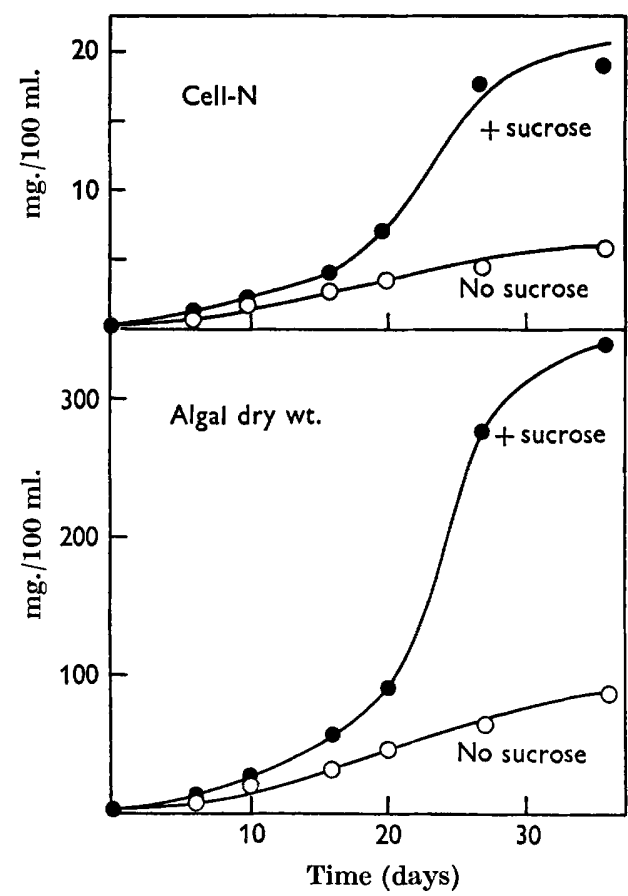

Fig. 3

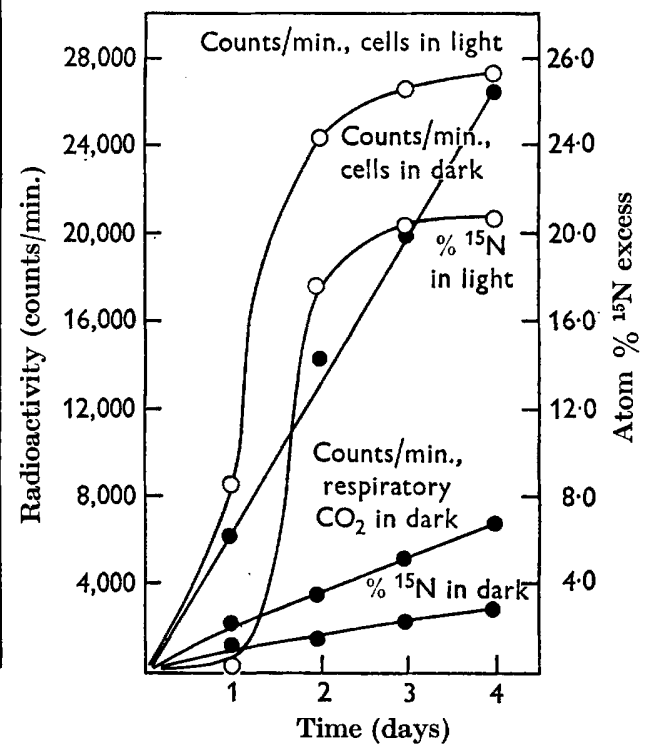

Fig. 4

Fig. 3. Effect of $0.01 \mathrm{~m}$-sucrose in the medium upon growth (algal dry wt.) and nitrogen fixation (cell-N) of Chlorogloea fritschii incubated in the light (300 foot-candles) at $25^{\circ}$ with continuous shaking.

Fig. 4. Relations of ${ }^{14} \mathrm{C}$-sucrose assimilation and ${ }^{15} \mathrm{~N}_{2}$ fixation in Chlorogloea fritschii. $4 \mathrm{ml}$. algal suspensions were incubated in Warburg flasks at $30^{\circ}$ in the light $(650$ footcandles) and in the dark. Sucrose added at $0.001 \mathrm{~m}$ concentration and labelled with $0.5 \mu \mathrm{c}(\mathrm{U})^{14} \mathrm{C}$-sucrose per flask. Pardee buffer provided $0.2 \% \mathrm{CO}_{2}$ in side arms of light incubated flasks. Respiratory $\mathrm{CO}_{2}$ trapped in $10 \% \mathrm{NaOH}$ in the side arms of dark incubated flasks. Gas phase: $0.2 \mathrm{~atm}$. $\mathrm{N}_{2}$ enriched with $20 \%{ }^{15} \mathrm{~N}_{2}, 0.2 \mathrm{~atm}$. $\mathrm{O}_{2}$ and the rest argon. Open circles : incubated in light; solid circles : incubated in dark.

\section{Effects of sucrose upon ${ }^{15} \mathrm{~N}_{2}$ uptake in the light and in the dark}

Table 3 illustrates the effect of various experimental conditions on the rate of ${ }^{15} \mathrm{~N}_{2}$ incorporation by both strains of the alga. It was highest in the light and in the presence of sucrose, and was then not significantly affected by the supply or omission of external oxygen; like growth it exceeded more than 4 times the rate observed in the light without sucrose.

${ }^{15} \mathrm{~N}_{2}$ uptake continued to an appreciable extent in the absence of sucrose, i.e. in the purely inorganic medium in the dark. Though nitrogen fixation in the dark with sucrose was greater under aerobic conditions, it proceeded at a considerable rate also under anaerobic conditions. The light-grown strain fixed more nitrogen than the dark-adapted strain in the dark under aerobic but not under anaerobic conditions. 


\section{Relations between sucrose assimilation and nitrogen fixation}

Figure 4 represents a time course of ${ }^{14} \mathrm{C}$-sucrose assimilation and ${ }^{15} \mathrm{~N}_{2}$ fixation in the light and in the dark. ${ }^{14} \mathrm{C}$-incorporation in the light proceeded exponentially at first but slowed down after 2 days and became stationary after 4 days as a result of sucrose exhaustion from the medium. ${ }^{14} \mathrm{C}$-incorporation in the dark showed a linear course and reached finally a similar value to that in the light at the end of the incubation period. ${ }^{15} \mathrm{~N}_{2}$ fixation in the light, after a slow start, continued at an exponential rate and then followed a similar course to ${ }^{14} \mathrm{C}$-incorporation in the light. ${ }^{15} \mathrm{~N}_{2}$ was taken up at a much lower rate in the dark and this corresponded to the rate of respiratory ${ }^{14} \mathrm{CO}_{2}$ output in the dark.

Table 4. ${ }^{14} \mathrm{C}$-sucrose assimilation and ${ }^{15} \mathrm{~N}_{2}$ fixation in Chlorogloea fritschii in the light (600 foot-candles) and in the dark, with and without $\mathrm{CO}_{2}$ in the gas phase

$5 \mathrm{ml}$. algal suspensions, taken from a $\mathrm{N}$-starved culture, were incubated in Warburg flasks for $6 \mathrm{hr}$. at $35^{\circ}$ with continuous agitation. Sucrose added at $0.001 \mathrm{~m}$ concentration and labelled with $0.5 \mu \mathrm{c}(\mathrm{U})^{14} \mathrm{C}$-sucrose per flask. Pardee buffer in side arms provided $0.2 \% \mathrm{CO}_{2}$ for the light-incubated flasks. Respiratory $\mathrm{CO}_{2}$ trapped by $12 \%$ $\mathrm{KOH}$ in the side arms of the dark-incubated flasks. Gas phase: $0 \cdot 2 \mathrm{~atm}$. $\mathbf{N}_{2}$ enriched with $20 \%{ }^{15} \mathrm{~N}_{2}, 0.2 \mathrm{~atm} . \mathrm{O}_{2}$ and the rest argon. Means in parentheses.

\begin{tabular}{|c|c|c|c|}
\hline \multirow[b]{2}{*}{ Treatment } & \multicolumn{2}{|c|}{ Radioactivity } & \multirow[b]{2}{*}{$\begin{array}{l}\text { Atom \% } \\
{ }^{15} \mathbf{N}_{2} \text { excess }\end{array}$} \\
\hline & $\begin{array}{c}\text { Of cells } \\
\text { (counts/min.) }\end{array}$ & $\begin{array}{c}\text { Of respira- } \\
\text { tory } \mathrm{CO}_{2} \\
\text { (counts } / \mathrm{min} \text {.) }\end{array}$ & \\
\hline Light $+\mathrm{CO}_{2}$ & $\left.\begin{array}{l}18,060 \\
17,770\end{array}\right\}(17,915)$ & - & $\left.\begin{array}{l}0 \cdot 685 \\
0 \cdot 665\end{array}\right\}(0 \cdot 675)$ \\
\hline Dark $+\mathrm{CO}_{2}$ & $\left.\begin{array}{r}9,430 \\
11,350\end{array}\right\}(10,390)$ & - & $\left.\begin{array}{l}0 \cdot 095 \\
0 \cdot 090\end{array}\right\}(0 \cdot 093)$ \\
\hline Light $-\mathrm{CO}_{2}$ & $\left.\begin{array}{l}29,550 \\
30,930\end{array}\right\}(30,240)$ & $\left.\begin{array}{r}135 \\
55\end{array}\right\}$ & $\left.\begin{array}{l}0 \cdot 4.15 \\
0 \cdot 340\end{array}\right\}(0 \cdot 378)$ \\
\hline Dark $-\mathrm{CO}_{2}$ & $\left.\begin{array}{l}15,500 \\
15,770\end{array}\right\}(15,635)$ & $\left.\begin{array}{l}4,410 \\
4,870\end{array}\right\}(4,640)$ & $\left.\begin{array}{l}0 \cdot 100 \\
0 \cdot 112\end{array}\right\}(0 \cdot 106)$ \\
\hline
\end{tabular}

The results of a short term experiment, in which the effects of $\mathrm{CO}_{2}$ on ${ }^{14} \mathrm{C}$-sucrose assimilation and ${ }^{15} \mathrm{~N}_{2}$ fixation were investigated, are presented in Table 4. Omission of $\mathrm{CO}_{2}$ from the gas phase resulted in a marked increase of ${ }^{14} \mathrm{C}$-incorporation into cell material in the light, and also in the dark. About $25 \%$ of the recovered radioactivity was found in the respiratory $\mathrm{CO}_{2}$ in the dark. No appreciable radioactivity was, however, recovered as respiratory $\mathrm{CO}_{2}$ in the light. ${ }^{15} \mathrm{~N}_{2}$ fixation was greatest in the light in the presence of $\mathrm{CO}_{2}+$ sucrose. ${ }^{15} \mathrm{~N}_{2}$ fixation decreased when sucrose was the sole source of carbon for the organisms in the light and was still less in the dark. ${ }^{15} \mathrm{~N}_{2}$ fixation in the dark was slightly lower in the presence of $\mathrm{CO}_{2}$ than in its absence.

\section{DISCUSSION}

The finding that sucrose was outstanding among the substrates tested in allowing a considerable growth of Chlorogloea fritschii in the dark and also in supporting a reasonable rate of nitrogen fixation under heterotrophic conditions, contrasts with 
the reports about other blue-green algae (Allison et al. 1937; Allen, 1952; Kiyohara et al. 1960, 1962) for which glucose was the best substrate for growth in the dark. The utilization of other sugars by $C$. fritschii was either limited, as with glucose, or was dependent on the presence of combined nitrogen in the medium, as with maltose. The failure to grow $C$. fritschii on Krebs cycle intermediates, other sugars and organic compounds, all of which are probably intermediates or products of metabolic cycles, can best be explained by an inability to penetrate the cell membrane (Danforth, 1962).

On the first transfer from photosynthesizing conditions, growth of Chlorogloea fritschii in the dark proceeded rather slowly and only after a relatively long period of adaptation to heterotrophic conditions. Similar observations were reported by Allison et al. (1937) for Nostoc muscorum and by Allen (1952) for several other bluegreen algae. With $C$. fritschii the duration of this lag phase decreased markedly after adapting the alga to heterotrophic conditions by repeated subcultivation in the dark. Successful adaptation to these conditions was indicated also by the higher rate of growth and nitrogen fixation and by the more effective utilization of sucrose. ${ }^{15} \mathrm{~N}_{2}$ uptake was inhibited in the dark under anaerobic conditions indicating that nitrogen fixation depended upon the oxidative assimilation of sucrose, though it continued, at a lower rate, also under conditions of anaerobic respiration.

The stimulation by light of sucrose assimilation in Chlorogloea fritschii may be connected with the abundant supply of high-energy phosphate generated in the photochemical reaction which could be used for the phosphorylation of sucrose, in a similar way as for the phosphorylation of glucose in green algae (Kandler, 1954; Simonis, 1956). Photoassimilation of sucrose in C. fritschii is indicated by the increased ${ }^{14} \mathrm{C}$-sucrose incorporation into cellular material when $\mathrm{CO}_{2}$ was absent from the gas phase. This shows that $\mathrm{CO}_{2}$ assimilation plays no part in the uptake of sucrose but a higher proportion of the photochemically generated high-energy phosphates could be available for the phosphorylation of sucrose. In the presence of both $\mathrm{CO}_{2}$ and sucrose, photoreduction of $\mathrm{CO}_{2}$ and photoassimilation of sucrose could occur simultaneously, as is indicated by the greatest ${ }^{15} \mathbf{N}_{2}$ fixation observed under these conditions. The incorporation of the fixed nitrogen was apparently enhanced by the ample supply of carbon skeletons.

Inter-relations between carbon assimilation and nitrogen fixation in Chlorogloea fritschii observed under photosynthesizing conditions (Fay \& Fogg, 1962) were also evident when growing the alga in the dark and comparing the rates of carbon and nitrogen assimilation. Hydrogen carriers produced in respiration were presumably available for the reduction of elementary nitrogen and the ammonia thus formed could be incorporated into compounds derived from the conversion of sucrose. When ${ }^{14} \mathrm{C}$-sucrose assimilation was inhibited by $\mathrm{CO}_{2}$ in the dark, this was reflected by the simultaneous decrease of ${ }^{15} \mathrm{~N}_{2}$ fixation.

Metabolic inter-relations between photosynthesis and nitrogen fixation in Anabaena cylindrica were reported by Fogg \& Than-Tun (1960), Cox, Fay \& Fogg (1964) and Cobb \& Myers (1964). It is, however, not clear how nitrogen fixation is stimulated by the photochemical reaction and how much the observed interrelations are the manifestation of an inter-dependence on the products of photosynthesis and nitrogen fixation, respectively. Nitrogen fixation in Chlorogloea fritschii can certainly continue in the dark in the absence of an external substrate and its extent 
will apparently depend upon the endogenous sources present. The higher nitrogenfixing activity of the light-grown strain, observed in a short-term experiment in the dark, may be attributed to a greater store of carbon skeletons and energy accumulated during the preceding period of illumination.

The results presented here support the suggestion of a functional linkage between photosynthesis and respiration in blue-green algae (Stanier \& van Niel, 1962; Jones \& Myers, 1963). Studies on the relations of nitrogen fixation and photosynthesis in cell-free preparations of Anabaena cylindrica (Cox et al. 1964) indicate that nitrogen fixation in this alga is located in the photosynthetic lamellae extending throughout the peripheral chromatoplasm. Experiments with cell-free preparations of Chlorogloea fritschii confirmed these results and have shown that photosynthesis, respiration and nitrogen fixation was greatest in the same particulate fraction (unpublished data). The chromatoplasm thus may be regarded as a single metabolic unit in the cells of blue-green algae, in which interactions of photosynthesis, respiration and nitrogen fixation are most likely.

This investigation was supported by grant from the Department of Scientific and Industrial Research. I am grateful to Professor G. E. Fogg for his helpful comments.

\section{REFERENCES}

Allen, M. B. (1952). The cultivation of Myxophyceae. Arch. Mikrobiol. 17, 34.

Allison, F. E., Hoover, S. R. \& Morris, H. J. (1937). Physiological studies with the nitrogen-fixing alga, Nostoc muscorum. Bot. Gaz. 98, 433.

Burris, R. H. \& Wilson, P. W. (1957). Methods for measurement of nitrogen fixation. Meth. Enzymol. 4, 355.

Совв, H. D. \& Myers, J. (1964). Comparative studies of nitrogen fixation and photosynthesis in Anabaena cylindrica. Amer. J. Bot. 51, 753.

Cox, R. M., FAY, P. \& FogG, G. E. (1964). Nitrogen fixation and photosynthesis in subcellular fractions of the blue-green alga Anabaena cylindrica. Biochim. biophys. Acta, 88, 208.

Danforth, W. F. (1962). Substrate assimilation and heterotrophy. Physiology and Biochemistry of Algae. Ed. by R. A. Lewin, p. 99. New York: Academic Press.

FAY, P. \& FogG, G. E. (1962). Studies on nitrogen fixation by blue-green algae. III. Growth and nitrogen fixation in Chlorogloea fritschii Mitra. Arch. Mikrobiol. 42, 310.

$F_{A Y}$, P., Kumar, H. D. \& FogG, G. E. (1964). Cellular factors affecting nitrogen fixation in the blue-green alga Chlorogloea fritschii. J. gen. Microbiol. 35, 351.

FoGg, G. E. (1956). The comparative physiology and biochemistry of the blue-green algae. Bact. Rev. 20, 148.

Fogg, G. E. \& Than-Tun (1960). Interrelations of photosynthesis and assimilation of elementary nitrogen in a blue-green alga. Proc. Roy. Soc. B, 153, 111.

Hulme, A. C. \& Narain, R. (1931). The ferricyanide method for the determination of reducing sugar. Biochem. J. 25, 1051.

Jones, L. W. \& Myers, J. (1963). A common link between photosynthesis and respiration in a blue-green alga (Anacystis nidulans). Nature, Lond., 199, 670.

Kandler, O. (1954). Úeber die Beziehungen zwischen Phosphathaushalt und Photosynthese. II. Gesteigerter Glucoseeinbau in Licht als Indikator einer lichtabhängigen Phosphorylierung. Z. Naturf. $9 b, 675$.

Kiyohara, T., Fujita, Y., Hatrori, A. \& Watanabe, A. (1960). Heterotrophic culture of a blue-green alga, Tolypothrix tenuis. J. gen. appl. Microbiol. (Tokyo), 6, 176.

Kiyohara, T., Fujita, Y., Hattori, A. \& Watanabe, A. (1962). Effect of light on glucose assimilation in Tolypothrix tenuis. J. gen. appl. Microbiol. (Tokyo), 8, 165. 
Pardee, A. B. (1949). Measurement of oxygen uptake under controlled pressures of carbon dioxide. J. biol. Chem. 179, 1085.

SrmonIs, W. (1956). Untersuchungen zur lichtabhängigen Phosphorylierung. II. Die Hemmung der $\mathrm{CO}_{2}$-Assimilation von Algen durch Glucose und der Einfluss von Phosphat. Z. Naturf. $11 b, 354$.

Stanier, R. Y. \& van Niel, C. B. (1962). The concept of a bacterium. Arch. Mikrobiol. 42,17 . 